Dental diseases in subjects with $\beta$-thalassemia major

Al-Wahadni AM, Taani D0 et al. Community Dent Oral Epidemio/2002; 30: 418-422

Thalassaemia was associated with higher caries experience.

Thalassaemia involves defective structure of globin and hypochromic anaemia. There are conflicting results in the few studies of dental diseases in thalassaemic patients. In this study, 61 patients with $\beta$-thalassaemia were compared with matched controls, in 2 groups aged 6-12 yrs and 13-18 yrs. Plaque scores were similar in subjects and controls.

In the $6-12$ yrs $\beta$-thalassaemia group, mean Gingival Index was 1.3 and probing depth was $2.3 \mathrm{~mm}$; controls scored 1.3 and $2.2 \mathrm{~mm}$; in the 13-18 yrs group, respective scores were 1.5 and $2.8 \mathrm{~mm}$, and 1.5 and $2.6 \mathrm{~mm}$ (all NS). However, mean DMFT for the younger $\beta$-thalassaemia group was 8.8 and for controls, 4.3; for the older group, respective scores were 13.0 and 5.6 (both $P<0.0001$ ).

The authors ascribe the increased caries to a lower level of preventive care because of preoccupation with life-threatening problems in these patients, as well as to possible differences in the host response, such as lower salivary IgA.

\section{PAEDIATRIC DENTISTRY}

Effectiveness of glass-ionomer (ART) and amalgam restorations in the deciduous dentition: results after 3 years

Taifour D, Frencken JE etal. Caries Res 2002; 36: 437-444

Glass ionomer treatment appeared more effective after 3 years.

This study compared 482 children who received glass ionomer atraumatic restorative treatment (ART: hand instruments only) with 353 who received minimal traditional amalgam (MTA) restorations. A total of 1891 restorations was placed by 8 dentists. Allocation was random, and there was a $22 \%$ dropout after 3 years' follow-up.

After 3 years, cumulative survival of single surface ART restorations was $86 \%$, and of MTA, 80\% $(P<0.05)$. For multiplesurface restorations, respective survival rates were $49 \%$ and $43 \%$ (NS). There was an operator effect in multiple-surface MTA restorations, but in no other type of restoration.

There were some factors which affected randomization, arising from difficulties in power supply in this Syrian centre: only ART could be used on days without electricity. The authors concluded that ART yielded better results under the conditions of the study.

\section{CARIOLOGY; DENTAL PUBLIC HEALTH}

\section{Evidence for reversal of the caries decline among Norwegian children}

Haugejordan 0, Birkeland JM Int J Paediatr Dent 2002; 12: 306-315

Caries in 5-year-olds has increased significantly.

In this study, data from the Public Dental Services and other Norwegian statistics were examined to identify changes in caries status and explore possible reasons for them. In 1997, prevalence of caries with cavitation in 5-year-olds was 30\%; by 2000 it had increased to 39\%; in 12-year-olds the mean DMFT in 1997 was 2.3, and it reduced slightly to 2.2 by 2000 . Analysis of data from individual counties suggested that an increase might be likely in future years.

Whilst fluoride toothpaste is virtually universal in Norway, other factors showed some variation in recent years. Total annual sugar consumption per person over the past 20 years was $40-45$ $\mathrm{kg}$, but in 1997 it was $48 \mathrm{~kg}$. Fluoride tablet prescription has been more restricted since new recommendations in 1996. When other factors were controlled in multivariate analysis, caries at age 5 was the only predictor of caries at age 12 . The authors therefore predict a caries increase at age 12 in future years in the absence of remedial action.

ORAL MICROBIOLOGY; PHARMACOLOGY

\section{Susceptibility of Porphyromonas gingivalis in biofilms to amoxycillin, doxycycline and metronidazole}

Larsen T Oral Microbiol Immunol 2002; 17: 267-271

Biofilms markedly reduced bacterial susceptibility.

A biofilm is a bacterial defence system which can protect organisms from hostile substances such as antibiotics. This is why established deposits of dental plaque are notoriously insusceptible to the effects of antibiotics and antiseptic mouthrinses. In this study, six strains of $P$. gingivalis were used to produce biofilms in an anaerobic chamber, and minimal inhibitory and minimal bactericidal concentrations (MICs and MBCs) were measured for the three antibacterial drugs.

For biofilms, MIC of all three drugs was around twice that required for planktonic (non-biofilm) cultures with similar numbers of cell, and biofilm MBCs were generally 2-8 times higher than planktonic MBCs, but in some cases for doxycycline up to 64 times greater.

The authors consider that biofilms not removed by scaling could be responsible for some cases of 'refractory' periodontal disease, and advise particularly that bacteriostatic drugs like doxycycline should not be used where biofilms are involved. 